\section{G160 ASSOCIATION BETWEEN EXTERNAL AND INTERNAL DOSE OF DIESEL SOOT (BLACK CARBON) IN HEALTHY SCHOOLCHILDREN: A PILOT STUDY}

doi:10.1136/archdischild-2013-304107.172

'S Hussain, ${ }^{2} \mathrm{~J}$ Grigg, ${ }^{2} \mathrm{~N}$ Mushtaq, ${ }^{2}$ I Dundas, ${ }^{2} \mathrm{R}$ Brugha. ${ }^{1}$ School of Medicine, University of Cambridge, Cambridge, UK; ${ }^{2}$ Centre for Paediatrics, Barts and The London School of Medicine and Dentistry, London, UK

Aims Exposure to diesel soot (black carbon, BC) is linked to adverse health in children. A cross-sectional study reported that BC in airway macrophages (AM BC), a marker of inhaled dose of diesel soot, is associated with decreased lung function in healthy children [1]. These data are compatible with the reduction in growth of lung function associated with long-term exposure to elemental carbon reported in an 8 year epidemiological study of schoolchildren [2]. To date, the determinants of AM BC are unknown. This is an important evidence gap since it is unclear whether policy-makers should target background $\mathrm{BC}$, or peaks of freshly generated $\mathrm{BC}$ from roads. Using a newly developed portable monitor for BC, we sought to determine whether peaks in $\mathrm{BC}$ exposure are associated with airway macrophage black carbon (AM BC) in healthy schoolchildren. Methods Sputum inductions were carried out at schools as previously described [1]. Following processing, mean AM BC $\left(\mu \mathrm{m}^{2}\right)$ for 50 randomly selected AM was calculated using Image J software.

Personal exposure to $\mathrm{BC}$ was measured by a portable aethalometer (MicroAeth AE51, Magee Scientific). This monitor continuously samples BC in the air and data is downloaded after $24 \mathrm{~h}$ using the microAethCOM PC-based software (Fig 1). The number of peaks of $\mathrm{BC}$ above $10000 \mathrm{ng} / 300 \mathrm{sec}$ was determined for each child by inspection of the $24 \mathrm{~h}$ plot.

Results Twenty three children underwent sputum inductions. In the 15 children (65\%) who produced sufficient AM for analysis, the median AM BC was $0.26278 \mu \mathrm{m}^{2}$ (interquartile range (IOR) of 0.16164 to $0.42842 \mu \mathrm{m}^{2}$ ). Personal 24 hour BC data was obtained in 13/15 children. The median BC exposure was 783758 ng (IOR: 336583.5 to $1321364.5 \mathrm{ng}$ ). Exposure peaks were caused by the school journey and cooking.

No significant correlation was found between the number of peaks of carbon exposure above $10000 \mathrm{ng} / 300 \mathrm{sec}$ and average AM $\mathrm{BC}\left(\mu \mathrm{m}^{2}\right)$ (Fig 2). However the positive association $(\mathrm{r}=0.40$, Pearson coefficient) suggests that this pilot study may be underpowered.

Conclusion Linking external and inhaled dose of $\mathrm{BC}$ is feasible in schoolchildren, and may provide important insights into the determinants of inhaled dose of BC.

\section{REFERENCES}

1. Kulkarni N, Pierse N, Rushton L, Grigg J. “Carbon in airway macrophages and lung function in children." The New England Journal of Medicine 6, 355 (2006): 21-30

2. Gauderman, WJ, E Avol, F Gilliland, H Vora, D Thomas, K Berhane, R McConnell, N Kuenzli, F Lurmann, E Rappaport, H Margolis, D Bates and J Peters. "The effect of air pollution on lung development from 10 to 18 years of age." The New England Journal of Medicine 351, 11 (2004): 1057-1067.

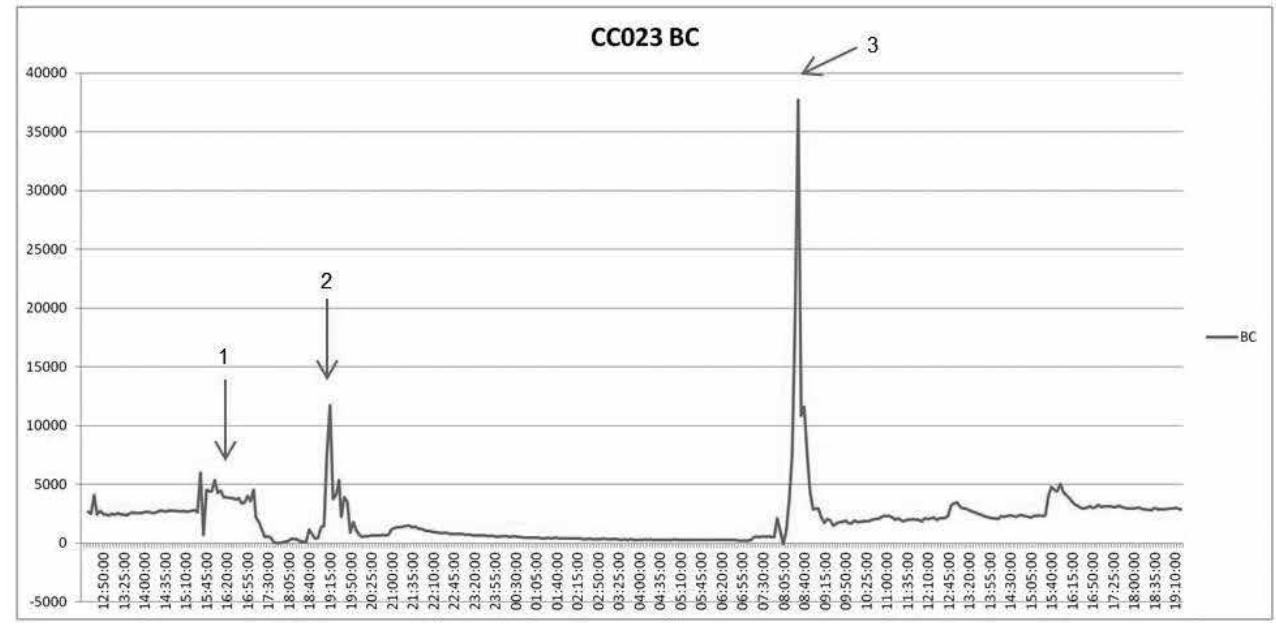

Abstract G160 Figure 1 Example 24 hour aethalometer trace. Peaks are associated with daily commute (1 and 3) and cooking (2).

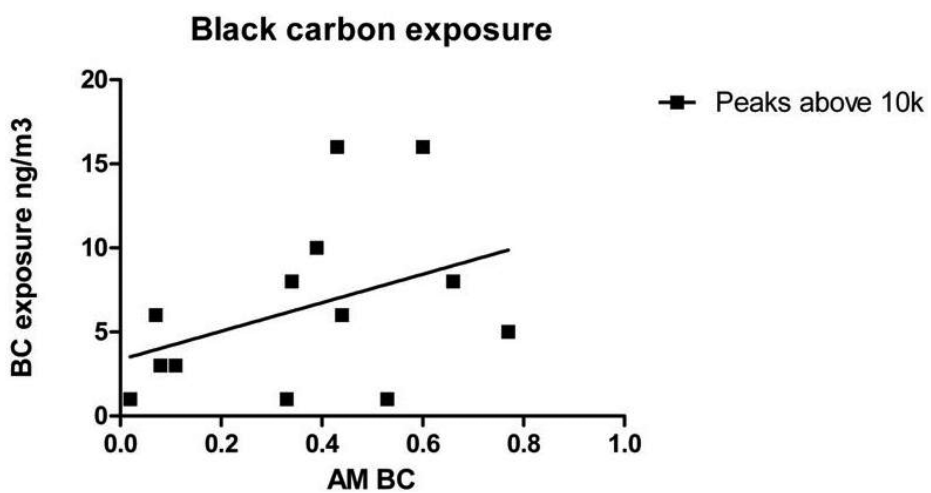

Abstract G160 Figure 2 Scatter graph showing AM BC vs. number of BC exposure peaks above $10000 \mathrm{ng} / 300 \mathrm{sec}$ The correlation coefficient for the number of peaks above $10000 \mathrm{ng} / 300 \mathrm{sec}$ against $A M B C(r=0.4028, n=13, p=0.1724)$ shows a non-significant positive correlation. 